\title{
Long term trend of chemical oxygen demand in Saroma-ko Lagoon, Japan; possible effects of climatic warming
}

\begin{abstract}
Akihiro Shiomoto
Tokyo University of Agriculture, 196 Yasaka, Abashiri 099-2493, Japan

E-mail: a3shiomo@bioindustry.nodai.ac.jp
\end{abstract}

A trend of shortening duration of ice coverage has been reported in many rivers, ponds and lakes around the world due to climatic warming ${ }^{1-4}$. The shortening will have much influence on organic production due to the greater supply of light intensity and hence on water quality. Chemical Oxygen Demand (COD), a useful measure of water quality, has been monitored over the past thirty years in Saroma-ko Lagoon, a boreal lake in Japan characterized by wintertime ice coverage ${ }^{5}$. Here the data set of water quality in the lagoon is analyzed to reveal long-term trends in COD and the influence of climatic warming on such trends. There has been a significant increasing trend, caused primarily by an abrupt increase in the early 1990s. However, the increase could not be explained by the increased load of organic matter on the lagoon from the river basin and organic production in the lagoon. On the other hand, periods of freezing of the entire surface have tended to be shorter with inevitable thinning of ice over the past forty years ${ }^{6}$, probably due to climatic warming. Ice and planktonic algae are exposed to the low light intensity in situ, which is not optimum for the algal production of organic matter $^{7-9}$. The shortening and thinning should thus bring an improvement in ambient light conditions for algae, resulting in an increase of organic matter in winter. Most of the organic matter possibly remains even after spring because of the low water 
temperature. It is highly possible that climatic warming promotes deterioration in water quality in ice-covered lakes.

Saroma-ko Lagoon, which is $150 \mathrm{~km}^{2}$ in area and $19.5 \mathrm{~m}$ in maximum depth, is located on the northeast coast of Hokkaido (ca. $44^{\circ} \mathrm{N}, 144^{\circ} \mathrm{E}$ ) and is connected to the Sea of Okhotsk by two narrow channels. The lagoon is characterized by wintertime ice coverage. Long-term monitoring of water quality has been carried out by the Hokkaido Government since the early $1970 \mathrm{~s}^{5}$. A trend of increasing COD has been noted during the past ten years ${ }^{10}$, arousing fear of worsening water quality. It has been suggested that the increase is due to an increase in the load of organic matter from the river basin ${ }^{10}$; however, a detailed study has not yet been conducted. Hence, the data set of COD during 1975-2006 was analyzed to reveal trends over the past thirty years and factors causing such trends. As a result, there has been a significant increase in COD over the past thirty years, though temporal and spatial variations were observed in each year $(\mathrm{P}<0.01$; Fig. 1a). For detailed analyses, the mean value in each year was investigated. The mean is affected by extremely high and low values but a significant linear relation was found between the mean and the median by using the data in this study from 1975 to $2006(\mathrm{r}=0.948, \mathrm{n}=32, \mathrm{p}<0.001)$, meaning that the mean values represent the COD in each year.

Relatively high mean values of COD were observed in 1975 and 1976 and an abrupt decrease occurred in 1977 (Fig. 1b). The second channel was opened in 1979 and the interaction of water between the ocean and the lagoon was therefore not as active in the two years. The lowest salinity and relatively low salinity were observed in 1975 and 1976, respectively (Fig. 1c), meaning a large inflow of river water. Remarkably high 
SS in 1975 supports the large inflow. The high COD can be due to a large load of organic matter into the lagoon due to the large inflow of river water.

The mean COD values shifted from 1977 to 1993 within a range of relatively low values, and neither a significantly increasing nor decreasing trend was found in the values in spite of year-to-year variation ( $\mathrm{P}>0.05$; Fig. 1b). An abrupt increase in mean COD was observed in 1994 and the mean COD values varied from 1994 to 2006 in a range of high values. Neither an increasing nor decreasing trend was significant during the twelve years $(\mathrm{P}>0.05)$, though an increasing trend was observed in the running mean (Fig. 1b). Furthermore, there was a significant difference between the COD values in 1977-1993 and in 1994-2006 (U test, $\mathrm{P}<0.01$ ) with a mean value in $1994-2006(2.5 \mathrm{mg} / \mathrm{L})$ that was 1.6 times higher than that in $1977-1993(1.6 \mathrm{mg} / \mathrm{L})$. The trend of increasing COD over the past thirty years can therefore be due to the high COD after 1994.

The COD test is to measure the amount of organic compounds in the water. There are thus three ways to account for the high COD after 1994. The first is an increase in the discharge of river water with organic compounds. Saroma-ko Lagoon has many rivers and thus variation in the inflow of river water appears as variation in salinity in the lagoon. Saroma-betsu River accounts for about $60 \%$ of the area of the river basin and about $80 \%$ of the inflow of all rivers ${ }^{11}$. The year-to-year trend in salinity from 1975 to 2006 was examined using the median surface salinity between May and November except October in each year reported at the station located the mouth of Saroma-betsu River (Fig. 1c). As a result, neither an increasing nor a decreasing trend was found during the thirty years $(\mathrm{P}>0.05)$ and there was furthermore no significant difference in salinity between 1977-1993 and 1994- 2006 (U test, 
$\mathrm{P}>0.05)$. In addition, Biological Oxygen Demand (BOD), an indicator of water pollutants, has been measured downstream from the river ${ }^{5}$. A significantly decreasing trend was found in mean BOD from 1975 to $2006(\mathrm{P}<0.05$; Fig. 1d). It can thus be said that the load of organic matter from the river basin has not increased over the past thirty years.

The second is an increase in organic production by phytoplankton (primary production) from spring to autumn in the lagoon. An increase in primary production should appear as an increase in chlorophyll $a$, an index of phytoplankton standing stock. Unfortunately, the data set provided by the Hokkaido Government does not have sufficient chlorophyll $a$ data to analyze long term trends. On the other hand, a sufficient data set has been prepared for transparency, which can be empirically related to variability in chlorophyll $a^{12}$. A significantly negative relationship was observed between transparency and chlorophyll $a$ reported in the lagoon using data previously reported $\left(\mathrm{r}_{\mathrm{s}}=-0.295, \mathrm{n}=518, \mathrm{p}<0.01\right)$, indicating that transparency also becomes an index of chlorophyll $a$ in the lagoon and hence primary production. Neither an increasing nor a decreasing trend was found in mean transparency $(\mathrm{P}>0.05$; Fig. 1e) and there was furthermore no significant difference in the values between in 1977-1993 and in 1994-2006 ( $\mathrm{U}$ test, $\mathrm{P}>0.05$ ). It can thus be said that organic production from spring to autumn has not increased during the past thirty years.

Saroma-ko Lagoon has been the site of a very successful scallop culture operation. Scallops excrete organic compounds. Thus, the third is an increase in the quantity of scallops being raised. Although the scale of the aquaculture operation varied year-to-year, a significant increasing trend was not found in the scale from 1975 to 2005 $\left(\mathrm{r}_{\mathrm{s}}=0.011, \mathrm{n}=31, \mathrm{P}>0.05\right)$ and there was no significant difference in quantities between 
1975-1993 and in 1994-2005 ( $\mathrm{U}$ test, $\mathrm{P}>0.05)^{6}$.

The above indicates that high COD after 1994 was not caused by an increase in organic compounds from spring to autumn, necessarily suggesting that high COD after 1994 was due to events during the winter. The freezing of the entire surface is a unique wintertime event at Saroma-ko Lagoon. A significantly deceasing trend was found in the period of the freezing of the entire surface from 1964 to 2007 (Fig. 1f; $\mathrm{P}<0.01)$. In particular, a remarkable trend of reduction was found from the late $1980 \mathrm{~s}$ to the early 1990 s. The monthly mean air temperature, monthly mean daily maximum temperature and monthly mean daily minimum temperature in Tokoro Town near Saroma-ko Lagoon tended to increase during the past thirty years (Fig. 1g; $\mathrm{P}<0.05$ ). Relatively high values were observed in the three temperature measures especially around 1990 (Fig. 1g). The warming of the air temperature has been indicated throughout Eurasia in some years since 1988 due to the climate regime $\operatorname{shift}^{13}$. The long term decreasing trend and remarkable reduction from the late 1980 s to the early 1990s are considered to be due to climatic warming and the climate regime shift, respectively.

The decrease in the periods of the freezing of the entire surface causes the thinning of ice while also reducing to area and duration of the ice coverage ${ }^{9}$, resulting in higher light intensity into the lower part of the ice and the seawater under the ice. In winter, ice algae in the lower part of the ice and phytoplankton in the seawater under the ice produce organic matter in the lagoon through photosynthesis ${ }^{14,15}$. Photosynthetic rates of both algae do not saturate at the in situ light intensity and maximum photosynthetic rates are several times higher than the rates at the in situ light intensity ${ }^{9,16,17}$. Organic production in Saroma-ko Lagoon in winter is thus easily expected to increase due to the 
shortening of the periods of the freezing of the entire surface. Furthermore, most of the organic matter produced possibly still remains with the coming of spring because of low temperatures during the winter, resulting in an increase in COD from spring to autumn. It would be no exaggeration to say that climate warming has contributed much to the high COD since 1994.

The periods of the freezing of the entire surface has decreased gradually since 1964 (Fig. 1f), implying a gradual increase in COD. It is a fact, however, that an abrupt increase in COD was found in 1994 as well as high COD since 1994 (Fig. 1b). The periods of the freezing of the entire surface have been less than 80 days since 1994 with the exception of 2001-2003, whereas a duration of less than 80 days was observed only in 1974 (0 days) and in 1982 (79 days) before 1993 (Fig. 1f). The shortening of the periods of the freezing of the entire surface improves light conditions for ice algae and phytoplankton and thus a duration of less than 80 days is considered to be a necessary condition for the occurrence of high COD in the lagoon. Durations during the period of the regime shift (1988-1993) were less than 80 days as well. However, air temperatures were high during the regime shift, implying high water temperature and hence acceleration in the consumption of organic matter. Thus, high COD possibly did not occur.

COD is composed of particulate and dissolved organic matter. There has been no increasing or decreasing trend in transparency, which is influenced by particulate matter (Fig. 1e), and the same result was found for suspended solids (SS) (P>0.05; Fig. 1h). There was no significant difference in SS between 1977-1993 and 1994-2006 (U-test, $\mathrm{P}>0.05$ ). Consequently, most of the high COD after 1994 is possibly composed of dissolved organic matter (DOM). An increase of DOM promotes microbial loop ${ }^{18,19}$, 
which then diminishes fish production ${ }^{20}$. It is possible that climatic warming promotes not only a deterioration in water quality in boreal lakes characterized by ice coverage but also the development of microbial loop and diminished fish production. In addition, global warming possibly deteriorates water quality through increase of organic production in winter. If global warming goes on, measures as usual, e.g. restriction of load of organic compounds, may not stop the progress in the deterioration in water quality.

\section{METHODS SUMMARY}

The items analyzed in this study were chemical oxygen demand (COD), salinity, transparency, chlorophyll $a$ and suspended solids (SS) in Saroma-ko Lagoon, biological oxygen demand (BOD) in Saroma-betsu River, periods of the freezing of the entire surface of Saroma-ko Lagoon and air temperature at Tokoro Town near Saroma-ko Lagoon. The COD, salinity, chlorophyll $a$, transparency, SS and BOD were cited from the annual reports of the Results of Water Quality Survey of Public Water Areas from FY 1975 to FY2006 ${ }^{5}$. Periods of the freezing of the entire surface were cited from the website of the Saroma-ko Aquaculture Union ${ }^{6}$. Air temperature was cited from the Climatic Statistics on the website of the Meteorological Agency of Japan ${ }^{21}$. The COD, salinity, transparency and BOD were obtained from 1975 to 2006 (32 years), the freezing periods from 1964 to 2007 (44 years) and air temperatures from 1977 to 2006 (30 years).

The surface data $(0.5 \mathrm{~m} \text { in depth) at seven stations (Stations } 1-7)^{5}$ located throughout the lagoon from May to November except October were used for analyzing COD, salinity, chlorophyll $a, \mathrm{SS}$ and BOD in this study. The methods for water sampling and 
analysis are found elsewhere ${ }^{5}$. COD was measured by the permanganate reflux

method. This method is inferior in oxidizing ability to the dichromate reflux method;

however, it poses no problems in elucidating trends over the past forty years. The

duration of complete ice coverage was monitored visually.

\section{References}

1. Schindler, D.W., Beaty, K.G, Fee, E.J., Cruikshank, D.R., DeBruyn, E.R., Findlay, D.L., Linsey, G.A., Shearer, J.A., Stainton, M.P. \& Turner, M.A. Effects of climatic warming on lakes of the central boreal forest. Science 250, 967-970 (1990).

2. Schindler, D.W., Bayley, S.E. \& Parker, B.R. The effects of climatic warming on the properties of boreal lakes and streams at the Experimental Lakes Area, northwestern Ontario. Limnol. Oceanogr, 41, 1004-1017 (1996).

3. Magnuson, J.J., Robertson, D.M., Benson, B.J., Wynne, R.H., Livingstone, D.M., Arai, T., Assel, R.A., Barry, R.G, Card, V., Kuusisto, E., Granin, N.G., Prowse, T.D., Stewart, K.M. \& Vuglinski, V.S. Historical trends in lake and river ice cover in the northern hemisphere. Science, 289, 1743-1746 (2000).

4. Futter, M.N. Patterns and trends in southern Ontario lake ice phenology. Environ. Monit. Assess. 88, 431-444 (2003).

5. Hokkaido Government. Results of the Water Quality Survey of Public Water Areas during FY1975 to FY2006 (1976-2006). The results of the Water Quality Survey are opened to the public in the net: http: //envgis.hokkaido-ies.go.jp/ index.asp?category = mizu; http://www.pref.hokkaido.lg.jp/ $\mathrm{ks} / \mathrm{khz} /$ contents/mizukankyo/down/ down.htm

6. Saroma-ko Aquaculture Union: http://homepage3.nifty.com/ saromako/

7. Satoh, H., Yamaguchi, Y., Watanabe, K. \& Aruga, Y. Light conditions and photosynthetic productivity of ice algal assemblages in Lake Saroma, Hokkaido. Jpn. J. Phycol. 37, 274-278 (1989a).

8. Satoh, H., Yamaguchi, Y., Watanabe, K., Tanimura, A., Fukuchi, M. \& Aruga, Y. Photosynthetic nature of ice algae and their contribution to the primary production in lagoon Saroma Ko, Hokkaido, Japan. Proc. NIPR Symp. Polar Biol. 2, 1-8 (1989b).

9. Kudoh, S., Robineau, B., Suzuki, Y., Fujiyoshi, Y. \& Takahashi, > Photosynthetic acclimation and the estimation of temperate ice algal primary production in Saroma-ko Lagoon, Japan. J. Mar. Sys. 11, 93-109 (1997).

10. Anonymous, Lakes and Marshes in Hokkaido, revised edition (Hokkaido Institute of Environmental 
Sciences, Sapporo, 2005).

11. Takeuchi, T., Sakata, T. \& Hayase, Y. A study on environmental conservation in lagoon on cold regions. Rept. Civil Eng. Res. Inst. 92, 1-103 (1990).

12. Falkowski, P.G \& Wilson, C. Phytoplankton productivity in the North Pacific ocean since 1900 and implications for absorption of anthropogenic $\mathrm{CO}_{2}$. Nature 358, 741-743 (1992).

13. Watanabe, M. \& Nitta, T. Decadal changes in the atmospheric circulation and associated surface climate variations in the northern hemisphere winter. J. Climate 12, 494-510 (1999).

14. Kudoh, S. Responses of microalgal primary productivity to the reduction of sea ice coverage in Lake Saroma during winter. Bull. Plankton Soc. Jpan. 39, 155-156 (1993).

15. Watanabe, K., Satoh, H. \& Yamaguchi, Y. Phytoplankton and ice algae in Lake Saroma. Bull. Plankton Soc. Jpn. 39, 165-166(1993).

16. Priscu, C., Lizotte, M.P., Cota, G., Palmisano, A.C. \& Sullivan, C.W. Comparison of the irradiance response of photosynthesis and nitrogen uptake by sea ice microalgae. Mar. Ecol. Prog. Ser. 70, 201-210 (1991).

17. Lizotte, M.P., Sharp, T.R. \& Priscu, J.C. Phytoplankton dynamics in the stratified water column of Lake Bonney, Antarctica. Polar Biol. 16, 155-162 (1996).

18. Azam, F., Fenchel, T., Field, J.G, Gray, J.S., Meyer-Reil, L.A. \& Thingstad, F. The ecological role of water-column microbes in the sea. Mar. Ecol. Prog. Ser. 10, 257-263 (1983).

19. Azam,F. Microbial control of oceanic carbon flux: the plot thickens. Science 280, 694-696 (1998).

20. Williams, N. The Mediterranean beckons to Europe's oceanographer. Science 279, 483-484 (1998).

21. Meteorological Agency of Japan. Climatic Statistics (http:// www.jma.go.jp/jma/index.htm). 


\section{Figure legend}

Figure 1. Long-term changes in Saroma-ko Lagoon. (a) COD. Linear relationship shown by solid line $(r=0.297, n=1260, P<0.01)$ and Spearman rank correlation $\left(r_{s}=0.423, P<0.01\right)$ are significant. The number of data in each year is 21-42. (b) Mean COD. Bars indicate standard errors. Linear relationship shown by broken line $(\mathrm{r}=0.585, \mathrm{n}=32, \mathrm{P}<0.01)$ and Spearman rank correlation $\left(\mathrm{r}_{\mathrm{s}}=0.573\right.$, $\mathrm{P}<0.01)$ are significant from 1975 to 2006. Linear relationship $(\mathrm{r}=0.089, \mathrm{n}=17, \mathrm{P}>0.05)$ and Spearman rank correlation $\left(\mathrm{r}_{\mathrm{s}}=-0.003, \mathrm{P}>0.05\right)$ are not significant from 1977 to 1993 . Linear relationship $(r=0.077, n=13, P>0.05)$ and Spearman rank correlation are not significant $\left(r_{s}=-0.033\right.$, $\mathrm{P}>0.05$ ) from 1994 to 2005. Gray line shows 3-years running mean. (c) Median salinity. Bars indicate standard errors. Linear relationship by broken line $(r=0.198, n=30, P>0.05)$ and Spearman rank correlation $\left(\mathrm{r}_{\mathrm{s}}=0.114, \mathrm{P}>0.05\right)$ are not significant. The number of data in each year is 20-41. Gray line shows 3-years running mean. (d) Mean BOD. Bars indicate standard errors. Linear relationship shown by broken line $(r=-0.365, n=32, P<0.05)$ and Spearman rank correlation $\left(r_{s}=-0.447\right.$, $\mathrm{P}<0.05$ ) are significant. The number of data in each year is 3-6. Gray line shows 3-years running mean. (e) Mean transparency. Bars indicate standard errors. Linear relationship shown by broken line $(r=-0.285, n=32, P>0.05)$ and Spearman rank correlation $\left(r_{s}=-0.274, P>0.05\right)$ are not significant. Gray line shows 3-years running mean. (f) Periods of the freezing of the entire surface. Linear relationship shown by broken line $(r=-0.576, n=44, P<0.01)$ and Spearman rank correlation $\left(r_{s}=-0.747\right.$, $\mathrm{P}<0.01$ ) are significant. Gray line shows 4-years running mean. (g) Monthly mean air temperature (solid diamond), monthly mean daily maximum temperature (solid square) and monthly mean daily minimum temperature (solid triangle) in Tokoro Town near Saroma-ko Lagoon. Linear relationships shown by broken lines $(\mathrm{r}=0.371-0.494, \mathrm{n}=29, \mathrm{P}<0.05)$ and Spearman rank correlation $\left(\mathrm{r}_{\mathrm{s}}=\right.$ 0.405-0.496, $\mathrm{P}<0.05$ ) are significant. Gray line shows 3-years running mean. (h) Mean suspended solid (SS). Bars indicate standard errors. Linear relationship shown by broken line $(r=-0.251, n=31$, $\mathrm{P}>0.05)$ and Spearman rank correlation $\left(\mathrm{r}_{\mathrm{s}}=-0.309, \mathrm{P}>0.05\right)$ are not significant. The number of data in each year is 21-42. Gray line shows 3-years running mean. 

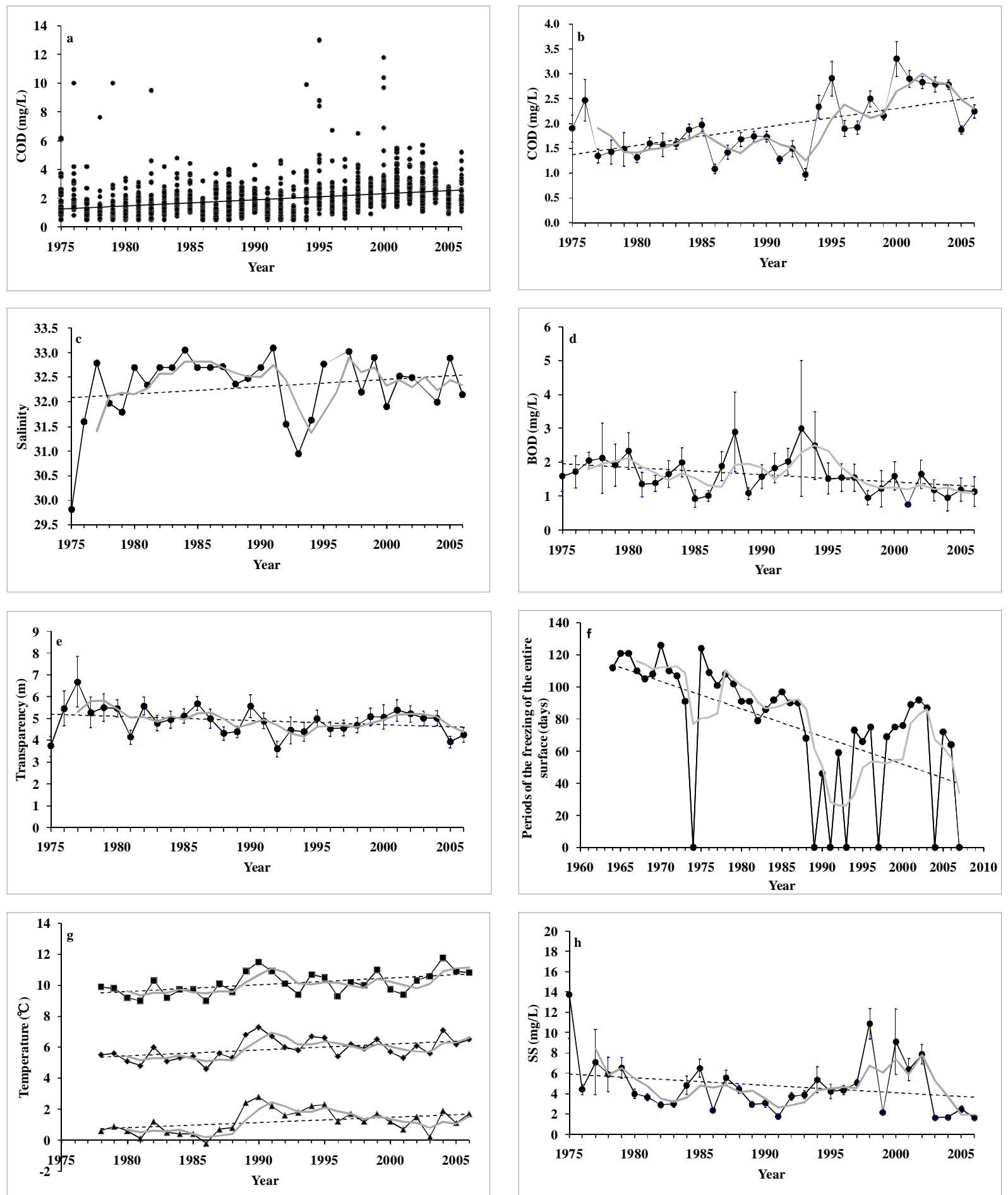

Figure 1 